\title{
Clozapine Normalizes Prefrontal Cortex Dopamine Transmission in Monkeys Subchronically Exposed to Phencyclidine
}

\author{
John D Elsworth*,', J David Jentsch',2, Bret A Morrow', D Eugene Redmond Jr' and Robert H Roth' \\ 'Neuropsychopharmacology Research Unit, Departments of Psychiatry and Pharmacology, Yale University School of Medicine, New Haven, \\ $C T$, USA
}

\begin{abstract}
The mechanism responsible for the therapeutic effects of the prototypical atypical antipsychotic drug, clozapine, is still not understood; however, there is persuasive evidence from in vivo studies in normal rodents and primates that the ability to elevate dopamine neurotransmission preferentially in the prefrontal cortex is a key component to the beneficial effects of clozapine in schizophrenia. Theoretically, such an effect of clozapine would counteract the deficient dopaminergic innervation of the prefrontal cortex that appears to be part of the pathophysiology of schizophrenia. We have previously shown that following repeated, intermittent administrations of phencyclidine to monkeys there is lowered prefrontal cortical dopamine transmission and impairment of cognitive performance that is dependent on the prefrontal cortex; these biochemical and behavioral changes therefore model certain aspects of schizophrenia. We now investigate the effects of clozapine on the dopamine projections to prefrontal cortex, nucleus accumbens, and striatum in control monkeys and in those withdrawn from repeated phencyclidine treatment, using a dose regimen of clozapine that ameliorates the cognitive deficits described in the primate phencyclidine (PCP) model. In normal monkeys, clozapine elevated dopamine turnover in all prefrontal cortical, but not subcortical, regions analyzed. In the primate PCP model, clozapine normalized dopamine (DA) turnover in the dorsolateral prefrontal cortex, prelimbic cortex, and cingulate cortex. Thus, the present data support the hypothesis that the therapeutic effects of clozapine in this primate model and perhaps in schizophrenia may be related at least in part to the restoration of DA tone in the prefrontal cortex.

Neuropsychopharmacology (2008) 33, 49I-496; doi:I0.I038/sj.npp. I 30 I448; published online I6 May 2007
\end{abstract}

Keywords: clozapine; dopamine; phencyclidine; prefrontal cortex; schizophrenia, monkey

\section{INTRODUCTION}

Atypical antipsychotic drugs have been traditionally distinguished from typical ones by their decreased proclivity to induce extrapyramidal side effects and an absence of sustained prolactin elevation. Clozapine was the original atypical antipsychotic drug used in the treatment of schizophrenia, and in contrast to typical agents, it improves the positive symptoms, negative symptoms, and cognitive dysfunction of schizophrenia (Kane et al, 1988; Lee et al, 1994; Meltzer and McGurk, 1999). Typical antipsychotics have rarely been reported to produce significant improvement in negative symptoms or cognitive function in

\footnotetext{
*Correspondence: Dr JD Elsworth, Department of Psychiatry, Yale University School of Medicine, 300 George St, 8300 Suite, New Haven, CT 065 I I, USA, Tel: + I 203785 4506,

E-mail: john.elsworth@yale.edu

${ }^{2}$ Current address: Department of Psychology, University of California, Los Angeles, PO Box 951563, CA 90095, USA.

Received 27 September 2006; revised 2 April 2007; accepted 4 April 2007
}

schizophrenia, yet these symptoms are considered the most difficult problem in schizophrenia. The cognitive problems consist of poor memory and attention, impaired executive and verbal functions, and deficits of psychomotor and sensory capabilities, and these features combine to impair psychosocial function dramatically and powerfully in schizophrenia (Elvevag and Goldberg, 2000). Thus, the cognitive symptoms of schizophrenia are a target of intensive research, both to uncover the relevant pathophysiological determinants and to highlight potential pharmacotherapeutic strategies.

Despite much research, the unique mechanism(s) responsible for the superior effects of clozapine are still not fully understood. However, there is strong evidence that clozapine preferentially elevates dopamine (DA) neurotransmission in the prefrontal cortex, and that this might be an important ingredient of its therapeutic effects (Moghaddam and Bunney, 1990; Karoum and Egan, 1992; Youngren et al, 1994; Broderick and Piercey, 1998; Kuroki et al, 1999; Melis et al, 1999; Youngren et al, 1999; Westerink et al, 2001). This hypothesis is compelling because reduced 
dopaminergic innervation to the prefrontal cortex occurs in schizophrenia (Akil et al, 1999; Egan et al, 2001; Guo et al, 2003), and dysfunction of the prefrontal DA system is thought to contribute to the cognitive deficits of the disorder (Davis et al, 1991; Knable and Weinberger, 1997; Goldman-Rakic et al, 2004).

The success of efforts to enhance cognition in schizophrenia depends, to some extent, on the availability of preclinical models that represent the relevant symptomatic features sufficiently to permit invasive and/or exploratory research not possible in humans (Green and Braff, 2001; Jentsch, 2003; Castner et al, 2004; Floresco et al, 2005; Hagan and Jones, 2005; Robbins, 2005). Non-human primate models are of particular impact, in as much as they can be assessed for cognitive functioning using tasks with both face and construct validity with relative ease.

Our previous work has shown that repeated treatment of monkeys with phencyclidine (PCP) results in a marked and persistent reduction in DA, but not serotonin or norepinephrine, turnover in the prefrontal cortex (Jentsch et al, 1997b, 1999a). As a change in DA turnover does not occur in striatal regions following repeated PCP administration, the effect induced in the primate PCP model on the prefrontal DA system is anatomically and neurochemically specific. Furthermore, the extent of impact of drug on DA innervation to the dorsolateral prefrontal cortex correlates significantly with the degree of cognitive impairment when performing an object retrieval with a detour (ORD) task, which is dependent on prefrontal cortex function (Jentsch et al, 1999a). Thus, the primate PCP model and its associated PFC DA deficit and cognitive dysfunction is well suited for a biochemical investigation of clozapine's action relevant to its therapeutic ability to reverse the cognitive dysfunction observed in this model and in schizophrenia.

We have previously shown that clozapine $(1 \mathrm{mg} / \mathrm{kg}$ daily for 3 days) improves performance of the ORD task in the primate PCP model (Jentsch et al, 1997c). Thus, we decided to test the hypotheses that this dosing regimen of clozapine elevates DA turnover in the dorsolateral prefrontal cortex of control monkeys and those previously exposed to PCP and that in PCP-treated monkeys this increase is sufficient to normalize DA turnover. Until recently it was widely believed that antipsychotic drugs have a delayed onset of action. Based on recent specific new studies and metaanalysis of previous studies, there is now appreciation that therapeutic action occurs early on, even within the first $24 \mathrm{~h}$ of treatment (Agid et al, 2003, 2006; Kapur et al, 2005; Leucht et al, 2005). These data support the relevance of the clozapine treatment paradigm employed in the current study.

\section{MATERIALS AND METHODS}

Young adult male or female St Kitts green (vervet) monkeys (Chlorocebus aethiops sabaeus) at the St Kitts Biomedical Research Foundation (St Kitts, West Indies) were used. As the subjects were feral monkeys, their exact age was not known. These studies were approved by the relevant institutional animal care and use committee. Monkeys, housed individually in squeeze-cages, were injected with $0.3 \mathrm{mg} / \mathrm{kg}$ PCP hydrochloride (Sigma-Aldrich, St Louis,
MO) or saline twice daily for 14 days, as described before (Jentsch et al, 1997c). Clozapine (1 mg/kg daily for 3 days) or clozapine vehicle was injected for 3 days, following our previous regimen (Jentsch et al, 1997b), starting 7 or 8 days after completion of PCP or saline treatment. Some monkeys that did not receive clozapine were not injected with clozapine vehicle, and received no injections between the termination of 14 days of PCP or saline treatment and sacrifice; the biochemical values for these monkeys were pooled with those that received clozapine vehicle, as no significant difference between them existed. Animals were rapidly euthanized $90 \mathrm{~min}$ after the final clozapine dose by an injection of sodium pentobarbital, as before (Jentsch et al, 1997b, 1999a). Brains were perfused with cold saline by cardiac perfusion until the fluid exiting fell below $10^{\circ} \mathrm{C}$. After transferring the brain in ice-cold saline to the dissection area, it was cut into $4 \mathrm{~mm}$ coronal slices using a custom brain mold. The following brain regions were rapidly dissected from slices on a thermostatically controlled refrigerated surface maintained at $1-2^{\circ} \mathrm{C}$ (Jentsch et al, 1997a, b; Elsworth et al, 2000): dorsolateral prefrontal cortex (Walker's Area 46), prelimbic cortex (Area 32), cingulate cortex (Area 24), supplementary motor area (Area $6 \mathrm{M})$, dorsolateral caudate nucleus, and nucleus accumbens (enriched in the core sub-region). The caudate nucleus sample was taken from a coronal slice through the 'head' of the region. Tissue samples were assayed for concentrations of DA and its major metabolite in primate brain, homovanillic acid (HVA), by HPLC as described elsewhere (Elsworth et al, 1996, 2000). The ratio of HVA/DA in each tissue was used as an index of DA turnover. Mean values of the dependent variable were compared between groups using two-factor ANOVA (PCP/saline pretreatment, and clozapine/vehicle treatment), followed by Contrasts analysis (SuperANOVA, Abacus Concepts, Berkeley, CA), declaring significance at the 0.05 level.

\section{RESULTS}

As shown in Figure 1, withdrawal from repeated treatment with PCP resulted in a significant decrease in DA turnover, as measured by HVA/DA ratio, in the dorsolateral prefrontal cortex, prelimbic cortex, and cingulate cortex. No significant change in this ratio occurred in supplementary motor area, nucleus accumbens or caudate nucleus.

Clozapine treatment elevated the index of DA turnover in all analyzed prefrontal cortical regions of normal and PCPexposed monkeys. However, in neither examined subcortical region did clozapine raise DA turnover. Inspection of the raw data indicated that for the prelimbic, cingulate, and supplementary motor area the raised ratio was mainly due to changes in HVA level. For the dorsolateral prefrontal cortex, a decrease in DA level contributed significantly to the increase in HVA/DA ratio.

Table 1 shows the control levels of DA for the different regions analyzed, derived from monkeys that received only saline and/or vehicle injections. There was no significant difference in basal DA concentration between any of the cortical regions. As expected, the control level in the caudate nucleus was greater than in the nucleus accumbens, and both these subcortical regions contained substantially 


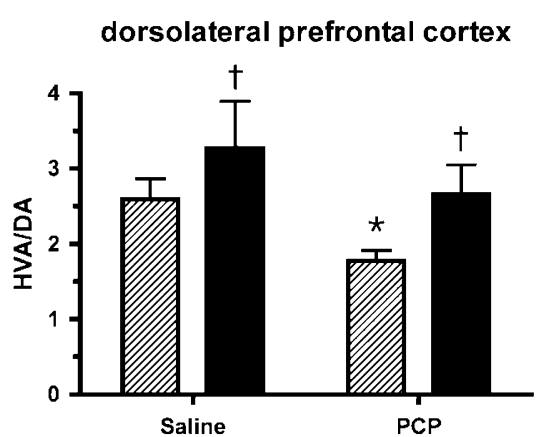

supplementary motor area

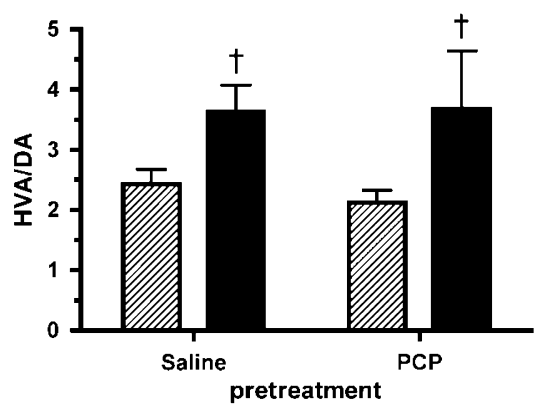

prelimbic cortex

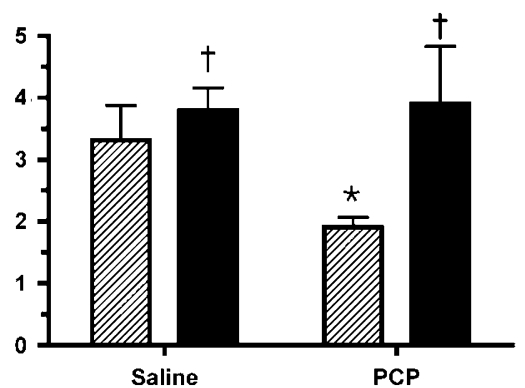

nucleus accumbens

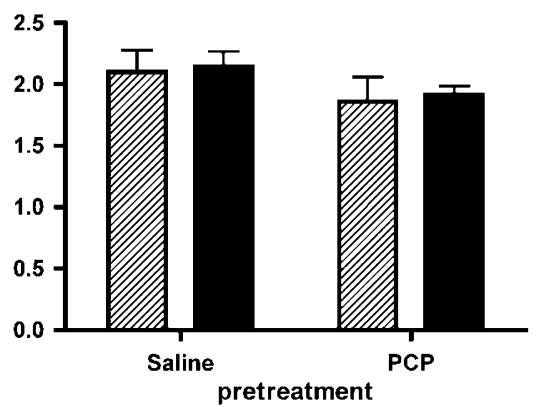

cingulate cortex

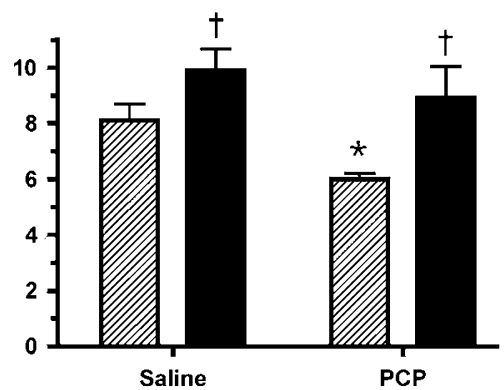

caudate nucleus

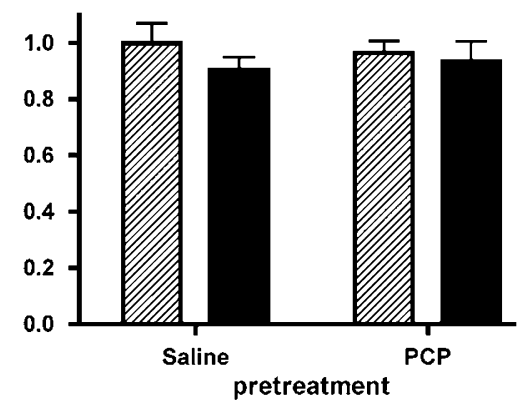

challenge with 200 Vehicle

Clozapine

Figure I Clozapine causes a preferential increase in dopamine turnover in cortical regions compared with subcortical brain regions in normal and PCPpretreated monkeys. ${ }^{\dagger}$ Clozapine significantly different from vehicle challenge (main effect for the four cortical regions, $F=13.1-4.8, P<0.00 \mathrm{I}-0.05$ ). * PCP pretreatment-vehicle challenge significantly different from saline pretreatment-vehicle challenge (contrast analysis for three significant cortical regions, $\mathrm{F}=6.3-4.9, P<0.02-0.05)$. HVA and DA values (mean\% control \pm SEM) for the clozapine-treated animals were as follows: dorsolateral prefrontal cortex; saline-clozapine $93 \pm 9$ [HVA]/78 \pm 12 [DA], PCP-clozapine 99 \pm 19/90 \pm 9: prelimbic cortex; saline-clozapine I35 \pm I0/ I09 \pm I5, PCP-clozapine I35 \pm 35 /

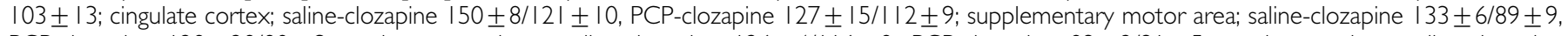
PCP-clozapine $128 \pm 28 / 80 \pm 3$; nucleus accumbens; saline-clozapine $126 \pm 4 / 116 \pm 8$, PCP-clozapine $89 \pm 2 / 9 \mid \pm 5$; caudate nucleus; saline-clozapine $99 \pm 5 / 107 \pm 6$, PCP-clozapine $90 \pm 9 / 93 \pm 3$. Numbers of monkeys in each group: saline-vehicle, 10-14; PCP-vehicle, 7-I3; saline-clozapine, 3-6; PCPclozapine, 3-4.

Table I Control Values ( \pm SE) for DA and HVA/DA in Different Monkey Brain Regions

\begin{tabular}{|c|c|c|}
\hline Region (n) & $\begin{array}{l}\text { Dopamine (ng/ } \\
\text { mg protein) }\end{array}$ & HVA/dopamine \\
\hline $\begin{array}{l}\text { Dorsolateral prefrontal } \\
\text { cortex (13) }\end{array}$ & $0.92 \pm 0.09$ & $2.60 \pm 0.26$ \\
\hline Prelimbic cortex (I0) & $1.27 \pm 0.16$ & $3.31 \pm 0.57$ \\
\hline Cingulate cortex (II) & $1.19 \pm 0.08$ & $8.11 \pm 0.59^{\mathrm{a}}$ \\
\hline Supplementary motor area (14) & $1.04 \pm 0.09$ & $2.43 \pm 0.24$ \\
\hline Nucleus accumbens (14) & $75.7 \pm 6.0^{b}$ & $2.10 \pm 0.18$ \\
\hline Caudate nucleus (14) & $127.0 \pm 6.6^{c}$ & $1.00 \pm 0.07^{\mathrm{d}}$ \\
\hline
\end{tabular}

Values were compared between regions by one-way ANOVA followed by Student-Newman-Keuls test (significance at $P<0.05$ ).

${ }^{a} H V A / D A$ ratio significantly greater than all other examined regions.

${ }^{b} \mathrm{DA}$ value significantly greater than the value in all cortical regions.

${ }^{\mathrm{C}} \mathrm{DA}$ value significantly greater than the value in all cortical regions and nucleus accumbens.

${ }^{d} H V A / D A$ ratio significantly lower than all other examined regions, $n$ is the number of monkeys in each group.

higher levels of DA than cortical regions. However, the HVA/DA ratio in control animals did not correlate with the DA concentration in each region, reflecting differences in intrinsic and extrinsic regulation between the DA projections (Elsworth and Roth, 2004), and possibly the relative density of norepinephrine innervation (Carboni and Silvagni, 2004). Notably, the HVA/DA ratio was higher in the cingulate cortex than any other regions measured, and the ratio in nucleus accumbens was not significantly different from most cortical regions despite having a far greater DA content.

\section{DISCUSSION}

Previous studies have examined biochemical indices of the effect of clozapine on DA neurons in normal and PCPtreated rodents (Jentsch and Roth, 2000), and the present data extend these investigations to the primate brain. Studies of the central actions of clozapine in a higher species are important because of primate-rodent differences in the anatomy and biochemistry of brain DA systems (Elsworth and Roth, 2004). The results from this study showed that clozapine elevated DA turnover in cortical, but not striatal, regions in monkeys. In addition, when administered at a dose that is effective at reversing the cognitive deficits associated with repeated PCP treatment in the monkey, clozapine normalized the PCP-induced reduc- 
tion in DA turnover in the dorsolateral prefrontal cortex, prelimbic cortex, and cingulate cortex.

We have previously shown using the microdialysis technique that clozapine administration preferentially increases extracellular DA levels in the dorsolateral prefrontal cortex compared with the caudate nucleus of normal monkeys (Youngren et al, 1999). Consistent with this finding, in the present study, we demonstrate that clozapine increased the HVA/DA ratio, an index of DA turnover, in post-mortem tissue from the prefrontal cortical regions examined, but not in tissue from nucleus accumbens or caudate nucleus. In the dorsolateral prefrontal cortex a decrease in DA level contributed significantly to the increase in HVA/DA ratio elicited by clozapine. In the mesoprefrontal DA system, where the recapture mechanism is inefficient (Ciliax et al, 1995; Sesack et al, 1998; Lewis et al, 2001) and transmitter homeostasis is more dependent on synthesis (Galloway et al, 1986), increases in functional activity can be reflected by a decrease in transmitter as well as an increase in metabolite level (Bean and Roth, 1991). It is not entirely clear why clozapine, but not typical antipsychotic drugs such as haloperidol, has a preferential action on cortical DA systems compared to the striatal DA systems. Although one feature that obviously distinguishes these areas is the density of DA innervation (Table 1), this does not in itself provide an explanation of the preferential action of clozapine on DA neurons projecting to the cortex. However, one of the early suggestions was that a selective action of clozapine on A10 DA neurons innervating the cortex, relative to A9 DA neurons projecting to the striatum may play a part in its observed preferential effects (eg Hand et al, 1987). While there have been several other theories over the years to explain the relative impact of clozapine on different DA systems, recent rodent data favor an explanation based on a difference in the local interaction of clozapine with receptors or uptake sites in the terminal regions (Gessa et al, 2000). The effect of a typical antipsychotic such as haloperidol could not be directly compared with the response to clozapine in the present study. This was because even a low dose of haloperidol $(0.025 \mathrm{mg} / \mathrm{kg}$ i.m. $)$ impairs cognitive performance in the monkey PCP model (Jentsch et al, 1999b), whereas 20-50 times this dose is required to elevate DA release in the dorsolateral prefrontal cortex (Youngren et al, 1999).

Repeated, intermittent exposure of monkeys to PCP produces a behavioral syndrome and neurochemical changes that may be relevant to the frontal cortical dysfunction characteristic of schizophrenia. The strong homology between the cognitive effects produced by PCP treatment and the frontal lobe impairment of schizophrenia support the notion that this model has face validity for the cognitive subsyndrome of the idiopathic disorder (Jentsch et al, 2000). Moreover, the striking similarities between neurochemical changes in the frontal cortex produced by long-term PCP administration and those evident in schizophrenia suggest that there may be construct validity for this model. Finally, our new neurochemical evidence together with behavioral data (Jentsch et al, 1999a) suggest that this model may have some predictive validity for the frontal cortical dysfunction of schizophrenia.

As we have shown before, DA turnover is reduced in some, but not all, prefrontal cortical regions following repeated PCP treatment in the monkey, a model that results in cognitive deficits on a task dependent on prefrontal cortical DA function (Jentsch et al, 1997b, c, 1998). In the present study, DA turnover was reduced by PCP in the dorsolateral prefrontal cortex, prelimbic cortex, and cingulate cortex, but not in supplementary motor area (Figure 1). In addition, no effect of repeated PCP on DA turnover in the caudate nucleus or nucleus accumbens was observed (Figure 1), as we have found before in the monkey and rat (Jentsch et al, 1997b,c). These changes implicate reduced dopaminergic transmission selectively in subregions of the prefrontal cortex of the monkey after repeated exposures to PCP.

In the present study, we were particularly interested to see whether clozapine, at a dose that reversed the cognitive deficits induced by repeated PCP in the monkey, would also normalize the reduced DA turnover produced in the primate PCP model. The present data show that in the dorsolateral prefrontal cortex, prelimbic cortex, and cingulate cortex, clozapine treatment returned the depressed PCP-induced DA turnover to the control level (Figure 1). Previously, we had shown that clozapine treatment in PCPpretreated rats raised extracellular DA levels significantly above that of normal rats (Jentsch and Roth, 2000). In another proposed animal model of aspects of schizophrenia, it has been found that rats raised in social isolation have an exaggerated dopaminergic response to acute clozapine in the prefrontal cortex (Heidbreder et al, 2001). This potentiation was not detected in the present primate study, and this may be important, as both deficient and excessive prefrontal cortex DA activation in primates result in working memory deficits (Arnsten et al, 1994; Murphy et al, 1996).

The data in Figure 1 are consistent with the conclusion that the ability of clozapine to alleviate preferentially the dopaminergic hypofunction induced by PCP in the dorsolateral prefrontal cortex, prelimbic cortex, and cingulate cortex is related to its ability to reduce cognitive impairment in PCP-treated monkeys. A critical test of this hypothesis will be to examine the comparative changes in the DA system and cognition in the primate PCP model produced by treatment with other atypical antipsychotic drugs. The present data also open up the possibility of investigating the receptor profile of clozapine that is responsible for its effect on the primate DA system and on cognition. Dopamine D4 receptors are highly enriched in the primate prefrontal cortex (Mrzljak et al, 1996) and as clozapine is a potent D4 antagonist, it has been suggested that this property might subserve some of its therapeutic effects in schizophrenia. It is noteworthy that our previous studies have demonstrated that a D4-selective antagonist, NGD-94-1, is able to reverse the cognitive deficits in the primate PCP model at a dose that has no significant effect on cognitive behavior in control monkeys (Jentsch et al, 1999b). In this study, an increase in CSF HVA was noted in the PCP monkeys, but not in control monkeys treated with NGD-94-1. The brain regions responsible for this change are unknown although previous studies have demonstrated a correlation between CSF and cortical levels of HVA in the monkey (Elsworth et al, 1987). Further studies will be required to determine if the behavioral reversal of the cognitive deficits in PCP-treated monkeys by NGD-94-1 or 
other selective D4 antagonists is associated with a restoration of DA tone in the PFC before one can implicate D4 receptors in the clozapine-induced changes observed in the current study.

The present data showing preferential augmentation of DA neurotransmission by clozapine in the dorsolateral prefrontal cortex and prelimbic cortex in the PCP primate model supports the idea that its therapeutic antipsychotic effects in schizophrenia may be related at least in part to the normalization of reduced DA innervation of the prefrontal cortex and sparing of striatal DA systems.

\section{ACKNOWLEDGEMENTS}

This work was supported by MH 57483. We thank Feng-Pei Chen for her excellent technical work, and the staff of St Kitts Biomedical Research Facility for their invaluable assistance.

\section{DISCLOSURE/CONFLICT OF INTEREST}

None of the authors has any conflict of interest.

\section{REFERENCES}

Agid O, Kapur S, Arenovich T, Zipursky RB (2003). Delayed-onset hypothesis of antipsychotic action: a hypothesis tested and rejected. Arch Gen Psychiatry 60: 1228-1235.

Agid O, Seeman P, Kapur S (2006). The 'delayed onset' of antipsychotic action-an idea whose time has come and gone. J Psychiatry Neurosci 31: 93-100.

Akil M, Pierri JN, Whitehead RE, Edgar CL, Mohila C, Sampson AR et al (1999). Lamina-specific alterations in the dopamine innervation of the prefrontal cortex in schizophrenic subjects. Am J Psychiatry 156: 1580-1589.

Arnsten AF, Cai JX, Murphy BL, Goldman-Rakic PS (1994). Dopamine D1 receptor mechanisms in the cognitive performance of young adult and aged monkeys. Psychopharmacology (Berl) 116: 143-151.

Bean AJ, Roth RH (1991). Extracellular dopamine and neurotensin in rat prefrontal cortex in vivo: effects of median forebrain bundle stimulation frequency, stimulation pattern, and dopamine autoreceptors. J Neurosci 11: 2694-2702.

Broderick PA, Piercey MF (1998). Clozapine, haloperidol, and the D4 antagonist PNU-101387G: in vivo effects on mesocortical, mesolimbic, and nigrostriatal dopamine and serotonin release. J Neural Transm 105: 749-767.

Carboni E, Silvagni A (2004). Dopamine reuptake by norepinephrine neurons: exception or rule? Crit Rev Neurobiol 16: 121-128.

Castner SA, Goldman-Rakic PS, Williams GV (2004). Animal models of working memory: insights for targeting cognitive dysfunction in schizophrenia. Psychopharmacology 174: 111-125.

Ciliax BJ, Heilman C, Demchyshyn LL, Pristupa ZB, Ince E, Hersch SM et al (1995). The dopamine transporter: immunochemical characterization and localization in brain. J Neurosci 15: 1714-1723.

Davis KL, Kahn RS, Ko G, Davidson M (1991). Dopamine in schizophrenia: a review and reconceptualization. Am J Psychiatry 148: 1474-1486.

Egan MF, Goldberg TE, Kolachana BS, Callicott JH, Mazzanti CM, Straub RE et al (2001). Effect of COMT Val108/158 Met genotype on frontal lobe function and risk for schizophrenia. Proc Natl Acad Sci USA 98: 6917-6922.
Elsworth JD, Roth RH (2004). Dopamine systems. In: Adelman G, Smith BH (eds). Encyclopedia of Neuroscience. CD-ROM: Elsevier: Amsterdam.

Elsworth JD, Brittan MS, Taylor JR, Sladek Jr JR, al-Tikriti MS, Zea-Ponce Y et al (1996). Restoration of dopamine transporter density in the striatum of fetal ventral mesencephalon-grafted, but not sham-grafted, MPTP-treated parkinsonian monkeys. Cell Transplant 5: 315-325.

Elsworth JD, Leahy DJ, Roth RH, Redmond Jr DE (1987). Homovanillic acid concentrations in brain, CSF and plasma as indicators of central dopamine function in primates. J Neural Transm 68: 51-62.

Elsworth JD, Taylor JR, Sladek Jr JR, Collier TJ, Redmond Jr DE, Roth RH (2000). Striatal dopaminergic correlates of stable parkinsonism and degree of recovery in old-world primates one year after MPTP treatment. Neuroscience 95: 399-408.

Elvevag B, Goldberg TE (2000). Cognitive impairment in schizophrenia is the core of the disorder. Crit Rev Neurobiol 14: 1-21.

Floresco SB, Geyer MA, Gold LH, Grace AA (2005). Developing predictive animal models and establishing a preclinical trials network for assessing treatment effects on cognition in schizophrenia. Schiz Bull 31: 888-894.

Galloway MP, Wolf ME, Roth RH (1986). Regulation of dopamine synthesis in the medial prefrontal cortex is mediated by release modulating autoreceptors: studies in vivo. J Pharmacol Exp Ther 236: 689-698.

Gessa GL, Devoto P, Diana M, Flore G, Melis M, Pistis M (2000). Dissociation of haloperidol, clozapine, and olanzapine effects on electrical activity of mesocortical dopamine neurons and dopamine release in the prefrontal cortex. Neuropsychopharmacology 22: 642-649.

Goldman-Rakic PS, Castner SA, Svensson TH, Siever LJ, Williams GV (2004). Targeting the dopamine D1 receptor in schizophrenia: insights for cognitive dysfunction. Psychopharmacology (Berl) 174: 3-16.

Green MF, Braff DL (2001). Translating the basic and clinical cognitive neuroscience of schizophrenia to drug development and clinical trials of antipsychotic medications. Biol Psychiatry 49: $374-384$

Guo N, Hwang DR, Lo ES, Huang YY, Laruelle M, Abi-Dargham A (2003). Dopamine depletion and in vivo binding of PET D1 receptor radioligands: implications for imaging studies in schizophrenia. Neuropsychopharmacology 28: 1703-1711.

Hagan JJ, Jones DN (2005). Predicting drug efficacy for cognitive deficits in schizophrenia. Schiz Bull 31: 830-853.

Hand TH, Hu XT, Wang RY (1987). Differential effects of acute clozapine and haloperidol on the activity of ventral tegmental (A10) and nigrostriatal (A9) dopamine neurons. Brain Res 415: 257-269.

Heidbreder CA, Foxton R, Cilia J, Hughes ZA, Shah AJ, Atkins A et al (2001). Increased responsiveness of dopamine to atypical, but not typical antipsychotics in the medial prefrontal cortex of rats reared in isolation. Psychopharmacology (Berl) 156: 338-351.

Jentsch JD (2003). Pre-clinical models of cognitive dysfunction in schizophrenia: new avenues to addressing unmet needs. Clin Neurosci Res 3: 303-315.

Jentsch JD, Elsworth JD, Redmond Jr DE, Roth RH (1997a). Phencyclidine increases forebrain monoamine metabolism in rats and monkeys: modulation by the isomers of HA966. $J$ Neurosci 17: 1769-1775.

Jentsch JD, Elsworth JD, Taylor JR, Redmond Jr DE, Roth RH (1998). Dysregulation of mesoprefrontal dopamine neurons induced by acute and repeated phencyclidine administration in the nonhuman primate: implications for schizophrenia. Adv Pharmacol 42: 810-814.

Jentsch JD, Redmond Jr DE, Elsworth JD, Taylor JR, Youngren KD, Roth RH (1997b). Enduring cognitive deficits and cortical 
dopamine dysfunction in monkeys after long-term administration of phencyclidine. Science 277: 953-955.

Jentsch JD, Roth RH (2000). Effects of antipsychotic drugs on dopamine release and metabolism in the central nervous system. In: Lidow L (ed). Neurotransmitter Receptors in Actions of Antipsychotic Medications. CRC Press: Boca Raton, FL. pp 31-41.

Jentsch JD, Taylor JR, Elsworth JD, Redmond Jr DE, Roth RH (1999a). Altered frontal cortical dopaminergic transmission in monkeys after subchronic phencyclidine exposure: involvement in frontostriatal cognitive deficits. Neuroscience 90: 823-832.

Jentsch JD, Taylor JR, Redmond Jr DE, Elsworth JD, Youngren KD, Roth RH (1999b). Dopamine D4 receptor antagonist reversal of subchronic phencyclidine-induced object retrieval/detour deficits in monkeys. Psychopharmacology (Berl) 142: 78-84.

Jentsch JD, Taylor JR, Roth RH (2000). Phencyclidine model of frontal cortical dysfunction in nonhuman primates. Neuroscientist 6: 263-270.

Jentsch JD, Tran A, Le D, Youngren KD, Roth RH (1997c). Subchronic phencyclidine administration reduces mesoprefrontal dopamine utilization and impairs prefrontal corticaldependent cognition in the rat. Neuropsychopharmacology 17: 92-99.

Kane J, Honigfeld G, Singer J, Meltzer H (1988). Clozapine for the treatment-resistant schizophrenic. A double-blind comparison with chlorpromazine. Arch Gen Psychiatry 45: 789-796.

Kapur S, Arenovich T, Agid O, Zipursky R, Lindborg S, Jones B (2005). Evidence for onset of antipsychotic effects within the first 24 hours of treatment. Am J Psychiatry 162: 939-946.

Karoum F, Egan MF (1992). Dopamine release and metabolism in the rat frontal cortex, nucleus accumbens, and striatum: a comparison of acute clozapine and haloperidol. Br J Pharmacol 105: 703-707.

Knable MB, Weinberger DR (1997). Dopamine, the prefrontal cortex and schizophrenia. J Psychopharmacol 11: 123-131.

Kuroki T, Meltzer HY, Ichikawa J (1999). Effects of antipsychotic drugs on extracellular dopamine levels in rat medial prefrontal cortex and nucleus accumbens. J Pharmacol Exp Ther 288: 774-781.

Lee MA, Thompson PA, Meltzer HY (1994). Effects of clozapine on cognitive function in schizophrenia. J Clin Psychiatry 55(Suppl B): $82-87$.
Leucht S, Busch R, Hamann J, Kissling W, Kane JM (2005). Earlyonset hypothesis of antipsychotic drug action: a hypothesis tested, confirmed and extended. Biol Psychiatry 57: 1543-1549.

Lewis DA, Melchitzky DS, Sesack SR, Whitehead RE, Auh S, Sampson A (2001). Dopamine transporter immunoreactivity in monkey cerebral cortex: regional, laminar, and ultrastructural localization. J Comp Neurol 432: 119-136.

Melis M, Diana M, Gessa GL (1999). Clozapine potently stimulates mesocortical dopamine neurons. Eur J Pharmacol 366: R11-R13.

Meltzer HY, McGurk SR (1999). The effects of clozapine, risperidone, and olanzapine on cognitive function in schizophrenia. Schizophr Bull 25: 233-255.

Moghaddam B, Bunney BS (1990). Acute effects of typical and atypical antipsychotic drugs on the release of dopamine from prefrontal cortex, nucleus accumbens, and striatum of the rat: an in vivo microdialysis study. J Neurochem 54: 1755-1760.

Mrzljak L, Bergson C, Pappy M, Huff R, Levenson R, GoldmanRakic PS (1996). Localization of dopamine D4 receptors in GABAergic neurons of the primate brain. Nature 381: 245-248.

Murphy BL, Arnsten AF, Goldman-Rakic PS, Roth RH (1996). Increased dopamine turnover in the prefrontal cortex impairs spatial working memory performance in rats and monkeys. Proc Natl Acad Sci USA 93: 1325-1329.

Robbins TW (2005). Synthesizing schizophrenia: a bottom-up, symptomatic approach. Schiz Bull 31: 854-864.

Sesack SR, Hawrylak VA, Matus C, Guido MA, Levey AI (1998). Dopamine axon varicosities in the prelimbic division of the rat prefrontal cortex exhibit sparse immunoreactivity for the dopamine transporter. J Neurosci 18: 2697-2708.

Westerink BH, Kawahara Y, De Boer P, Geels C, De Vries JB, Wikstrom HV et al (2001). Antipsychotic drugs classified by their effects on the release of dopamine and noradrenaline in the prefrontal cortex and striatum. Eur J Pharmacol 412: 127-138.

Youngren KD, Inglis FM, Pivirotto PJ, Jedema HP, Bradberry CW, Goldman-Rakic PS et al (1999). Clozapine preferentially increases dopamine release in the rhesus monkey prefrontal cortex compared with the caudate nucleus. Neuropsychopharmacology 20: 403-412.

Youngren KD, Moghaddam B, Bunney BS, Roth RH (1994). Preferential activation of dopamine overflow in prefrontal cortex produced by chronic clozapine treatment. Neurosci Lett 165: 41-44. 